\title{
Professional development opportunities for tutors of mathematics learning support
}

Michael Grove, School of Mathematics, University of Birmingham, Birmingham, UK. Email:

m.j.grove@bham.ac.uk.

Ciarán Mac an Bhaird, Department of Mathematics and Statistics, Maynooth University, Ireland.

Email: ciaran.macanbhaird@mu.ie.

Ciarán O'Sullivan, Department of Mechanical Engineering, Technological University Dublin Tallaght Campus, Dublin, Ireland. Email: Ciaran.OSullivan@TUDublin.ie.

\begin{abstract}
Deficiencies in the mathematical skills of students entering university study are having a negative impact on their education, and more broadly have serious consequences for society as a whole. Research demonstrates that extra initiatives established to give these students an opportunity to succeed are making a difference, and that the staff who provide these supports play a fundamental role. Here we review two different models of structured training that were developed for these tutors, via two cases studies drawn from within the UK and Ireland. We discuss the key and transferrable skills that these tutors require, skills that are often not typically needed in a more 'traditional' teaching role. The majority of tutors remain in this crucial support role for only a short period of their careers, and so a fundamental question remains as to how they can receive appropriate recognition for their academic endeavours. Such recognition is important for both the institution, in demonstrating its commitment to teaching quality, and for the career progression of the tutors themselves.
\end{abstract}

Keywords: mathematics support, tutor training, accredited provision.

\section{Introduction}

Mathematics learning support (MLS) is now a widely accepted means of helping students address the difficulties they encounter with the mathematical and statistical components of their studies, particularly as they make the transition to university study (Lawson, 2015). Student evaluations of MLS provision identify, almost without exception, the crucial role of MLS tutors in their success (O'Sullivan, Mac an Bhaird, Fitzmaurice and Ní Fhloinn, 2014). This reflects the unique MLS studenttutor relationship where one-to-one support is provided in a relaxed and non-threatening environment. Sound mathematical knowledge, and the ability to apply it, are presumed for an MLS tutor. However, the diverse and challenging nature of the teaching involved and the many different situations they may potentially encounter (Croft and Grove, 2011) means that tutors need to be appropriately trained and subsequently supported (mentored) by those with experience of working in such a teaching environment. In recent years, there has been a significant increase in the levels of training available for MLS tutors (Croft and Grove, 2016; Fitzmaurice, Cronin, Ní Fhloinn, O'Sullivan and Walsh, 2016) and this coincides with national moves to increase the number of staff within UK and Irish $\mathrm{HE}$ with a recognised teaching qualification. For example Marshall, in her forward to the 2015 UK Student Experience Survey (Buckley, Soilemetzidis and Hillman, 2015), comments on the results (p.3):

When asked to rank the importance of three different characteristics of the people they are taught by, students in nearly half of all subjects rate staff having received training in how to teach as the number one priority. When asked last year about priorities for institutional expenditure, a significant number of students chose better training for lecturers. 
In this paper, we focus on the key role of tutors in MLS, and present two case studies of MLS tutor training successfully established (not entirely independently) in the UK and Ireland. These training models are the culmination of a journey from ad hoc (institutional specific) training to structured regional/national models of training.

\title{
2. Background
}

The postgraduate teaching assistant, has a well-established and vital role in supporting teaching and learning within HE and one that requires specific support (National Research Council, 1991, p.27):

\begin{abstract}
Heavy reliance on the use of graduate teaching assistants, many of whom have limited experience or training for the responsibilities placed on them, has farreaching consequences...Few graduate students, however, are ready to serve well the educational needs of first-year college students...
\end{abstract}

Within the US, there has long been recognition of the importance of the postgraduate teaching assistant within the mathematical sciences. The Mathematical Association of America (MAA) within its Guidelines for Programs and Departments in Undergraduate Mathematical Sciences (MAA, 2003), makes it clear that "since they are the future faculty members of our colleges and universities, it is important that graduate students have some instruction in teaching including serving as apprentice teachers." (p.3). Furthermore, it adds: "Departments should provide long-term structured opportunities for acquisition and improvement of teaching skills by all who teach." (p.3). In comparison, perhaps the closest UK equivalent to this, the Quality Assurance Agency (QAA) for Higher Education Subject Benchmark Statement for Mathematics Statistics and Operational Research (QAA, 2015), a document designed to ensure the quality and standards for mathematics education in UK HE, currently makes absolutely no reference to training for those teaching or supporting the mathematical sciences within $\mathrm{HE}$.

Within the UK, a 2005 survey involving approximately 60 postgraduate students from the mathematical sciences and exploring their training needs (Cox and Kyle, 2005) highlighted that most $(70 \%)$ were involved in running seminars, tutorials, problem classes or other small group teaching of some kind in Mathematics or Statistics, $40 \%$ were involved in marking exams and about half marked coursework. Despite the far-reaching nature of their roles, postgraduates were increasingly reporting that they received little training or support for these duties: "Before embarking on my teaching duties as a postgraduate it always struck me as somewhat unusual that PhD students are able to and expected to be capable of undertaking such duties with very little (or if given) suitable training" (Lee, 2005, p.38). There are likely to be benefits for the undergraduates who receive the tutoring if the postgraduates have been appropriately trained. The postgraduates are not only better prepared to meet the needs and expectations of the undergraduate students they tutor, but they also develop their own skills, their confidence in teaching and receive a valuable preparation for a range of future academic and non-academic careers.

In more recent times the important role of postgraduate students working within a MLS environment has become increasingly apparent and this is coupled with the widespread growth of mathematics support observed across the UK and Ireland (Perkin, Croft and Lawson, 2013; Cronin et al., 2016). For example, in their analysis of recent surveys of MLS undertaken across the UK and Ireland, Grove, Croft and Lawson (2019) identified that out of 116 institutions, 53 were using postgraduate students as tutors within MLS. Further, amongst the 78 institutions they surveyed in 2018 within England and Wales as part of this work, there were seven institutions where mathematics support was provided solely by postgraduate students. 
MLS tutors have diverse mathematical backgrounds (Cronin et al., 2016; Grove, Croft and Lawson, 2019), mainly encompassing postgraduate and undergraduate students, full-time and part-time staff, and staff who are external to the institution. While some of these tutors may have experience gained from traditional teaching roles within the institution such as lecturing or tutoring within a department, MLS tutoring requires an additional and enhanced set of skills. In a sense, it is not tutoring, it is not small group teaching, it requires communication skills, human empathy, and the ability to allow other people to work and fail but within a supportive and non-judgmental environment; it is the ability to guide independent learning. Within MLS, tutors work with some of the most vulnerable students, those lacking confidence, those with specific learning difficulties, and those most at risk of dropping out. Increasingly, MLS is also being accessed by the specialist and more-able student (Grove, Guiry and Croft, 2019; Croft and Grove, 2015), one who is seeking to enhance and develop their mathematical skills and knowledge even further and occasionally beyond the boundaries of their module(s) of study.

While many MLS tutors may have had some prior training as department tutors or lecturers, they are, as noted by Croft and Grove (2016, p.3), "in the front line of tackling the lack of confidence and skill deficits of students who arrive at support centres looking for help". In addition to both their content knowledge and their ability to think on their feet (since student queries are rarely predictable in MLS), tutors need to facilitate a social environment where mathematics learning can take place (Solomon, Croft and Lawson, 2010). The importance of providing MLS in a non-judgmental, nonembarrassing and non-threatening environment (Lawson, Croft and Halpin, 2003; O'Sullivan et al., 2014) is key to giving learners an opportunity to talk about their mathematical problems and concerns.

With students themselves now being required to contribute a greater proportion towards the costs of their education within England and Ireland (see for example Higher Education and Research Act 2017 and Cassells (2016) respectively), there is evidence that their expectations in relation to their learning experience are changing. For example, the 2016 Student Academic Experience Survey (Neves and Hillman, 2016) concludes (p.5):

The student experience is still a positive one, but students as consumers are becoming more demanding. They are looking for evidence of value for money and are prepared to put in the effort themselves as long as they feel this is matched by being offered an involved experience with high-quality teaching, staff who continuously develop their skills, and appropriate levels of contact hours for the subject they choose.

This, and the now well-documented challenges associated with student learning of mathematics within a range of disciplines, has clear implications for how HEls can best support these learners to ensure that their programme of study not only meets their needs, in terms of future careers or further study, but also their expectations. Tackling this 'mathematics problem' is an area of priority for almost all HEls within the UK and Ireland and one where MLS and its tutors have a critical role (Cronin et al., 2016; Grove et al., 2018). Many of these tutors are postgraduates, and for postgraduates who choose to work within MLS, while doing so is known to be challenging, there are many benefits. Since many MLS tutors do not remain in MLS provision for their entire careers, they develop an extensive range of transferable skills that should place them at an advantage when seeking employment or an academic career. However, in order for their experience to be a productive and positive one, they require training and ongoing support, with recent evidence demonstrating that they continue to develop as tutors by being part of a community of their peers (Grove and Croft, 2019).

We now move to consider training for staff involved in teaching/tutoring or supporting students in their mathematical learning. Doing so however, raises a more fundamental issue relevant to all 
disciplines: how can such training be structured and accredited so that there exists an institutional record that training has taken place and that the individuals who participate have a formal and transferable record of their commitment to their professional development? Through our work, we have identified that such training and support may take one of three forms: ad hoc and nonaccredited; structured and non-accredited; and, structured and accredited.

Ad hoc training can perhaps be best described as MLS training designed within an individual institution as a one-off event. It would normally be given before a tutor begins in MLS, and provides essential information the tutor needs to manage typical situations that may arise. Structured training would be designed by a network of experienced MLS practitioners from a variety of institutions. It forms a programme, a regular series of activities, mentoring and support, which when combined offers a continued opportunity for tutors to develop and hone their skills. It would also allow for specific issues or challenges encountered to be discussed and advised on.

Non-accredited describes the situation where there is no formal acknowledgement or recognition that an individual has undertaken such training, and as such, there exists no record of their commitment to their professional development in a format which is easy for a tutor to evidence via a C.V. or a transcript of academic achievement. A record in this format is important for the institution and the individual: it demonstrates that training has not only taken place, but also that the individual possesses the required skills and abilities to perform their duties effectively. For the institution, this is important for demonstrating quality assurance while for the individual it can help in showcasing their skills as they look to make the transition to an academic career or employment.

The two case studies that follow, drawn from the UK and Ireland, illustrate structured and nonaccredited approaches that evolved to address the initial professional development needs of MLS tutors but which in their present form are not easily amenable to enabling tutors to gain formal accreditation for the skills and expertise developed.

\section{Case Study 1: Training staff who work in MLS within the UK}

For many years there has been significant work within the US to ensure appropriate training, support and guidance for graduate teaching assistants within the mathematical sciences was available, see for example Rishel (1999). However, within the UK, before 2005, there had been very little. In autumn 2005, the Maths, Stats \& OR (MSOR) Network, a national government funded disciplinary organisation with the mission of enhancing teaching and learning within the mathematical sciences in UK HE, set about changing this by introducing a series of one-day workshops aimed at postgraduate students who were teaching and supporting learning.

While we choose not to discuss these workshops here, further details of their structure can be found in Grove, Cox and Kyle (2006). They are important since they formed the subsequent model for a one-day workshop programme developed for those new to working in MLS. Through the National HE STEM Programme (Grove, 2013) a network was developed to assist those working in MLS across England and Wales. In 2010, this sigma Network (Croft et al., 2015), which sought to increase the extent of MLS provision and to share effective practice, identified there existed a pressing need to provide some form of initial training to the growing number of postgraduate students involved in the provision of front-line mathematics and statistics support to learners.

The training consisted of one-day workshops delivered by experienced members of the MLS community, who worked as facilitators rather than presenters. The focus for these events was clear, they were practical not theoretical. Further, the events were to be role and subject specific, that is, grounded in the reality of the duties tutors were likely to undertake when working in MLS and based firmly within the context of the discipline of mathematics. 
Table 1. Format of sigma workshops for postgraduates working in MLS.

Session

1. Welcome and introductions

2. Mathematics support what is it?

3. Problem solving

4. Principles of maths support - do's and don'ts

5. Offering statistics support

6. Tutoring in the
mathematics drop-in centre -
awareness of individual
differences and needs
7. Group activity - exploring
scenarios

8. Resources and networking with others

9. Question and answer session
Short Description

With a view to establishing interaction and identifying common themes, delegates are asked to spend a few minutes considering what they want to learn/gain from the day.

Participants are asked to explore ideas for what MLS is and how it is utilised by learners. The purpose is to develop interaction and help delegates obtain an understanding of the context of working in MLS.

Participants consider a range of problems in small groups. The purpose is not to solve these, but to consider how they will help guide students using their MSCs.

Delegates are asked to consider what they might do prior to, during or after working in the MSC.

Offering support in statistics is different to offering support in mathematics (Croft and Grove, 2016). Advice is provided on how to deal with statistical queries for tutors who are not specialist statisticians.

Students using MLS have a range of backgrounds, interests, and learning styles. Guidance is provided on the backgrounds of students who may use MLS with advice on how to support these.

Groups are given several wide-ranging scenarios that have arisen in existing MSCs and asked to discuss how they would respond.

A wealth of resources are now available for MLS. This session raises awareness of some of those that are freely available.

A final opportunity for delegates to explore aspects of the workshop in more detail or to have any questions they may have answered.

Based on participant feedback, three core principles underpinned the delivery of these workshops, and were critical to their success: practice sharing; an informal environment; and, interactivity. Although workshops were open to all working in MLS from across the UK HE sector, basing them within a HEI meant that often the majority of participants were drawn from that institution. Bringing together new tutors, who were typically postgraduates, was an ideal networking and social opportunity, aiding their adjustment to what might be a new place of study and, in terms of their work in MLS, it was critical for building an environment where there were other like-minded individuals they could approach for advice and guidance post-workshop. The workshops were deliberately designed to be informal; it was deemed essential to engage the postgraduates fully in the activities offered, but also allow them the opportunity to shape the overall direction taken within sessions to respond to their particular needs and concerns. The trainers identified that building an informal environment was key to developing this interactivity, and achieving this involves developing the confidence of participants to freely share their views and ideas throughout the workshop. It was highly noticeable that, as a result of the interactive mathematical tasks, interactivity and the willingness of individuals to contribute views and ideas increased throughout the day. 


\section{Case Study 2: Training staff who work in MLS in Ireland}

In Ireland, prior to 2009, the training of MLS tutors was developed and provided as a local activity within some of the individual MSCs. A 2008 audit of MLS provision (Gill, O'Donoghue and Johnson, 2008) found that only 2 of the 13 institutions who responded provided formal training for tutors. Due to the success of sigma within the UK, the Irish Mathematics Learning Support Network (IMLSN) was established in 2009. The newly formed IMLSN noted similar challenges and issues associated with the training of tutors amongst those institutions with MLS provision. Indeed, in 2011 the initial data analysis of the large-scale multi-institutional student evaluation of MLS (1633 first-year service mathematics students from nine HEls) (O'Sullivan et al., 2014), the importance of the tutor role in MLS was so strongly identified by the respondents that the IMLSN gave immediate priority to the design of a structured training programme for MLS tutors on the island of Ireland. The training programme comprised of an amalgamation of tutor training materials designed by members of the IMLSN, whilst making suitable use of proven strategies and materials from within the sigma guide (Croft and Grove, 2011). A suite of four workshops to be run over one day was developed, as outlined in table 2. Extensive use of sigma materials was made for Workshops 1 and 3 , and existing tutor training materials were largely used for Workshop 2 . Workshop 4 was a combination of material from the UK along with bespoke material developed in Ireland so as to give a voice to the experiences of existing Irish tutors. As an example of the community approach to the development of these workshops, a document with five 'Do's and Don'ts' in MLS was written by an experienced Irish MLS tutor and used for Workshop 4 initially. Subsequently, a survey was developed and distributed across the IMLSN to try and establish the most common Do's and Don'ts in an Irish context, the findings from which were then incorporated into the workshop training materials.

In September 2013 and 2014 a selection of these workshops were piloted in individual HEls and facilitators of the training commented that they had worked well and were very well received by tutors. However, this suite of workshops had not been implemented in a way that was accessible to all institutions within the IMLSN and so at that stage had limited impact across the IMLSN. In fact, data gathered in April 2015, as part a review of MLS provision within Ireland, showed that tutor training was provided in only 11 of the 25 of institutions with MLS (Cronin et al., 2016). This reinforced the importance of the IMLSN facilitating a co-ordinated tutor training programme, accessible to as many MLS practitioners as possible. Therefore, in 2015 the IMLSN undertook a national project to further build the capacity of MLS tutors in a structured pan-institutional format by implementing the four pilot workshop MLS tutor training programme in a coordinated way, open to all members of the IMLSN, and subsequently to evaluate the programme of workshops and their impact. The National Forum for the Enhancement of Teaching and Learning in Higher Education (National Forum) under its Disciplinary Network Funding funded the project.

In September 2015, the IMLSN conducted their structured but non-accredited tutor training programme in three institutions, with invitations extended to all MLS tutors across all HEls on the island of Ireland. The training followed that of the previously piloted one-day four-workshop model. Forty-two tutors from six HEls participated (Fitzmaurice et al., 2016). In September 2016, the training was offered again in a similar format and advertised across the IMLSN membership. 
Table 2. Aims and objectives of the four IMLSN workshops for MLS tutors.

\begin{tabular}{|c|c|}
\hline Workshop title & Short Description \\
\hline $\begin{array}{l}\text { 1. Mathematics } \\
\text { Learning Support: } \\
\text { Why is it important } \\
\text { and how can we } \\
\text { improve it? }\end{array}$ & $\begin{array}{l}\text { Aim: To outline the typical mathematical ability of students who require } \\
\text { MLS and how to interact effectively with them. } \\
\text { This workshop should enable tutors to: } \\
\text { (i) Recognise that many students enter HE with relatively poor levels of } \\
\text { mathematical ability; } \\
\text { (ii) Note the mathematical topics where there are clear gaps in student } \\
\text { understanding. } \\
\text { (iii) Develop ways of dealing with scenarios, which are commonly } \\
\text { encountered during MLS sessions. }\end{array}$ \\
\hline $\begin{array}{l}\text { 2. Working with } \\
\text { students: } \\
\text { Explaining, } \\
\text { Listening, } \\
\text { Questioning Skills }\end{array}$ & $\begin{array}{l}\text { Aim: To equip tutors with the skills they need in explaining, listening and } \\
\text { questioning so that they will be able to employ positive strategies of } \\
\text { engagement with students who seek MLS. This workshop should enable } \\
\text { tutors to: } \\
\text { (i) Use active listening techniques in working with students in MLS. } \\
\text { (ii) Select and use appropriate types of questions in helping students } \\
\text { mathematically. } \\
\text { (iii) Employ strategies to engage positively with students seeking MLS. }\end{array}$ \\
\hline $\begin{array}{l}\text { 3. Individual } \\
\text { differences and } \\
\text { needs: Scenarios } \\
\text { you might } \\
\text { encounter in } \\
\text { mathematics } \\
\text { support }\end{array}$ & $\begin{array}{l}\text { Aim: To enhance tutors' awareness of both the implications of the non- } \\
\text { academic differences between students and the range of situations that can } \\
\text { occur as a result of diverse student approaches to learning. This workshop } \\
\text { should enable tutors to: } \\
\text { (i) Recognise the importance of individual (non-academic) differences } \\
\text { and needs amongst students, to understand how these can impact on } \\
\text { student engagement and to be aware of appropriate interaction with the } \\
\text { students in these situations. } \\
\text { (ii) Be aware of the range of motivational factors and approaches to } \\
\text { learning that are adopted by students, and to be able to respond } \\
\text { appropriately to the variety of situations that may occur. }\end{array}$ \\
\hline $\begin{array}{l}\text { 4. Developing as a } \\
\text { Tutor: The Do's } \\
\text { and Don'ts. }\end{array}$ & $\begin{array}{l}\text { Aim: To establish a framework of knowledge and techniques to enable } \\
\text { tutors to develop as tutors in their future work in MLS. This workshop } \\
\text { should enable tutors to: } \\
\text { (i) Identify the positive impact that MLS can have on students. } \\
\text { (ii) Assimilate the insights of experienced tutors of MLS into their } \\
\text { practice. } \\
\text { (iii) Use techniques of reflection on key competencies to improve their } \\
\text { skills as an MLS tutor on an ongoing basis. }\end{array}$ \\
\hline
\end{tabular}

\section{Discussion}

\subsection{Perception of training}

The workshops developed for postgraduates working in MLS were a natural evolution of those developed for postgraduates who teach. They share many common features in their design and implementation, but most significantly they were delivered at a national level through the funded MSOR and sigma Networks; the former no longer exists, and the latter now exists as an unfunded 
community of practice. Most significantly, both sets of workshops were an example of structured but non-accredited professional development provision.

For each of the MLS workshops that have been run within the UK, delegate feedback has been collected. This has not focused upon obtaining quantitative ranking scores, but instead on obtaining specific comments that can be used to develop the events through a feedback loop. Feedback particularly emphasises the three underpinning principles: practice sharing; an informal environment; and interactivity. For example: 'clear explanation on things to do, not to do and things to expect nice mixture of interactive sessions, lots of new resources'; 'very dynamic, interactive and easy going. Helped me get a bit more confidence as to my ability to be a good tutor'; and, 'it gave me a list of resources that should help with solving some of the...problems'.

Another key feature of the feedback was that delegates welcomed the opportunity 'to network' and 'share ideas'. This is a clear indication of the importance of providing such training provision through a network particularly as within a number of institutions providing mathematics support is known to be a solitary endeavour (Grove, Croft and Lawson, 2019). Typical feedback includes: 'opportunity for group discussion on individual problems in own maths/stats support centre'; 'sharing experiences with other people - knowing about what other universities are offering and the methods of support available'; 'interaction with other would be tutors - advice from lecturers on how to aid others'; and, 'the brainstorming part of the event was important in terms of knowing each other's approach in dealing with different scenarios that may occur. Lateral thinking approach to solving questions that might be asked was equally important'.

\subsection{Impact of training}

While this immediate feedback is reassuring, a key question remains as to whether the training continues to influence postgraduate tutoring practices when working with undergraduates in the medium to longer-term. For the UK model discussed above, there exists some evidence that those postgraduates who have participated in the training have used this to inform their approach to teaching. For example, the following quotes are from undergraduates who received MLS in the academic year 2016/17 within an institution where a compulsory training programme was run for all postgraduates involved in providing MLS; these quotes were taken between one and eight months after the initial training session and refer explicitly to the tutors who provided the support: 'explained things clearly, talked through steps well, gave good examples to help understanding', 'good communication, started from my knowledge so I knew what was going on', 'very good help, got me to the answers without giving away too much and explaining theory', and 'very helpful, made sure I understood by giving me time to work through problem independently after thorough explanation'.

Within Ireland, focus groups were conducted with postgraduates 10 weeks after the September 2015 training programme. Full details of the results of these are available in Fitzmaurice et al. (2016) but some of their key insights follow here. Tutors reported that the training programme was beneficial for their tutoring practice, and many recommended making it compulsory. Tutors were asked for suggestions on ways the training process could be enhanced for all practicing and prospective tutors. They suggested that: more time be dedicated to the development of tutors' questioning and assessment skills; they would like more training in teaching group/tutorial sessions. Furthermore, tutors requested greater use of role-playing of MLS scenarios be used in certain workshops.

As outlined previously, the Irish MLS tutor training events in 2015 occurred in three specific HEls, and tutors from other HEls were invited to attend. This system helped to establish a sense of community amongst all the tutors, and went some way towards addressing the feelings of isolation that some tutors reported while working in MLS. Tutors highlighted the importance of developing a mechanism to enable them to get to know other tutors, and allow them to feel as part of a team. The 
importance of these views are reinforced by the findings of more recent work (Grove and Croft, 2019).

Based on the evidence collected to date, the models described above would seem to address the substance of the initial training needs of staff who will work in MLS. Institutions should benefit significantly from employing such suitably trained tutors. Some evidence appears to indicate that tutors have benefited from the training, and as such have a range of skills that will greatly aid their progression to academic, or indeed a range of other diverse careers. However, accreditation is required to ensure that there is demonstrable validation to this effect.

\section{Conclusions and next steps}

The UK workshops were designed as stand-alone events which were non-accredited, however there is some limited evidence that HEls are accepting these in lieu of more generic forms of institutional training for postgraduates involved in teaching and supporting learning. For example, at the University of Birmingham all postgraduates involved in teaching must receive appropriate training and support. From 2016, the School of Mathematics agreed with the Centre for Learning and Academic Development, the organisation that offers centralised training to postgraduates from any discipline, that participating in a one-day event of the nature described can be accepted in lieu of three of the four generic courses that postgraduates would otherwise attend. Establishing the equivalence of these mathematics-specific activities with their institutional counterparts has been achieved through the mapping of the provision against the UK Professional Standards Framework (UKPSF, 2011) and then establishing its equivalence with existing provision within the institution.

The Irish training programme of workshops for MLS tutors was devised by the IMLSN and as such offers the opportunity for delivery in a wide number of institutions across a network which brings many benefits. However, the IMLSN forms an organisation that is in essence a community of practice and not one that is aligned to any professional development standards - in itself, it has no mechanism for accrediting its own, or indeed anyone else's training provision. The training workshops were structured and based upon individual institutional tutor training materials (some of these formed parts of accredited programmes) and certain key aspects of the sigma training, but nevertheless, they were non-accredited.

For the benefit of tutors who are at the front-line of providing a vital student focused service, and indeed their institutions who are now required to demonstrate a clear commitment to furthering teaching excellence, the current lack of accreditation of their training is a situation that needs to change to ensure tutors get the recognition their endeavours deserve. In the context of more highly developed structures of professional development, how to evolve from the structured and unaccredited training to one that is structured and can gain accreditation for the participant forms the next key challenge.

To meet this challenge, the authors have designed a model of tutor development that may be amenable to accreditation which is currently undergoing piloting within Ireland. Work on this model began in 2016 arising from discussions regarding tutor training in light of a newly published framework for professional development in HE in Ireland (National Forum, 2016), which took place at the 10th IMLSN annual conference (IMLSN 10) which was held in Galway, Ireland (Pfeiffer, Cronin and Mac an Bhaird, 2016). The essence of the model is to provide formal recognition for the professional development undertaken by an MLS tutor in a way that the tutor can then seek accreditation from their institution or a professional body. The model provides the potential to move from existing structured and non-accredited models to a structured and accredited model via a formal recognition step which makes use of micro-credentials. At the heart of the model are four microcredentials: MLS Knowledge and Skills; MLS Communication/Dialogue skills; MLS Professional 
Identity Development; MLS Digital Capacity. The micro-credentials can be stored and shared digitally by the tutor awarded them. Each micro-credential contains a description of the abilities which the tutor must develop and a description of the evidence that they must provide to show that they have demonstrated these abilities. The micro-credentials have been designed to equate to 5 ECTs postgraduate credits once all four have been completed. The MLS micro-credential model is designed to allow for delivery through a community of practice which ensures the training is provided by those with the most appropriate teaching knowledge, experience and expertise in the discipline, something not all institutions will have access to. Simultaneously the model could allow a national organisation to offer formal accreditation for the training against a universally recognised framework, for example the UKPSF, whilst also facilitating institutions to understand the equivalence of the activities undertaken and much more easily allow them to be recognised as an appropriate form of prior learning. Piloting of the micro-credentials is ongoing and initial tutor feedback has been positive so the model may form the future basis for tutor training that is structured and can gain accreditation for the participant. We intend to report on the micro-credential based model and the outcomes of this pilot in the near future.

\section{References}

Buckley, A., Soilemetzidis, I. and Hillman, N., 2015. The 2015 Student Academic Experience Survey. York, UK: The Higher Education Academy.

Cassells, P., 2016. Investing in National Ambition: A Strategy for Funding Higher Education. Report of the Expert Group on Future Funding for Higher Education. Dublin, Ireland: Department for Education and Skills.

Cox, W. and Kyle, J., 2005. Supporting Postgraduates who teach Mathematics and Statistics - A preliminary report on recent workshops. MSOR Connections, 5(4), pp.5-6.

Croft, T. and Grove, M.J., 2016. Mathematics and Statistics Support Centres: Resources for Training Postgraduates and Others Who Work in Them. MSOR Connections, 14(3), pp.3-13. https://doi.org/10.21100/msor.v14i3.305

Croft, T. and Grove, M.J., 2015. Progression within mathematics degree programmes. In M. Grove, T. Croft, J. Kyle, and D. Lawson, eds. Transitions in Undergraduate Mathematics Education. Birmingham, UK: University of Birmingham and Higher Education Academy. pp.173-189.

Croft, T. and Grove, M.J. eds., 2011. Tutoring in a Mathematics Support Centre: A Guide for Postgraduate Students. Available at: http://www.mathcentre.ac.uk/resources/uploaded/46836tutoring-in-msc-web.pdf [Accessed 15 May 2019].

Croft, T., Lawson, D., Hawkes, T., Grove, M., Bowers, D. and Petrie, M., 2015. sigma - a network working! Mathematics Today, 50(1), pp.36-40.

Cronin, A., Cole, J., Clancy, M., Breen, C. and O'Sé, D., 2016. An audit of Mathematics Learning Support provision on the island of Ireland in 2015. Available at: http://www.sigmanetwork.ac.uk/wp-content/uploads/2019/02/Audit-of-MLS-provision-Ireland.pdf [Accessed 15 May 2019].

Fitzmaurice, O., Cronin, A., Ní Fhloinn, E., O’Sullivan, C. and Walsh, R., 2016. Preparing Tutors for Mathematics Learning Support. MSOR Connections, 14(3), pp.14-20.

https://doi.org/10.21100/msor.v14i3.307 
Gill, O., O'Donoghue, J. and Johnson, P., 2008. An audit of mathematics support provision in Irish third level institutions. Limerick, Ireland: Regional Centre for Excellence in Mathematics Teaching and Learning, University of Limerick.

Grove, M., 2013. National HE STEM Programme - Final Report. Birmingham, UK: University of Birmingham. Available at: https://www.birmingham.ac.uk/Documents/collegeeps/college/stem/national-he-stem-programme-final-report.pdf [Accessed 15 May 2019].

Grove, M. and Croft T., 2019. Learning to be a postgraduate tutor in a mathematics support centre. International Journal of Research in Undergraduate Mathematics Education, 5(2), pp.228-266. https://doi.org/10.1007/s40753-019-00091-8

Grove, M.J., Croft, A.C. and Lawson, D.A., 2019. The extent and uptake of mathematics support in higher education: results from the 2018 survey. Manuscript accepted for publication in Teaching Mathematics and its Applications.

Grove, M.J., Croft, T., Lawson, D. and Petrie, M., 2018. Community perspectives of mathematics and statistics support in higher education: building the infrastructure. Teaching Mathematics and its Applications, 37(4), pp.171-191. https://doi.org/10.1093/teamat/hrx014

Grove, M., Guiry, S. and Croft, T., 2019. Specialist and more-able mathematics students: understanding their engagement with mathematics support. Manuscript accepted for publication in International Journal of Mathematical Education in Science and Technology.

https://doi.org/10.1080/0020739X.2019.1603407

Grove, M.J., Kyle, J. and Cox, W., 2006. The Weakest Link? Supporting The Postgraduate Teaching Assistant. In D. Corcoran and S. Breen (Eds.), Proceedings of Second International Science and Mathematics Education Conference. Dublin, Ireland: St Patrick's College, Drumcondra, Dublin, pp.116-123.

Higher Education and Research Act 2017 (c.29). London: HMSO.

Lawson, D., 2015. Mathematics Support at the transition to university. In M. Grove, T. Croft, J. Kyle, and D. Lawson, eds. Transitions in Undergraduate Mathematics Education. Birmingham, UK: University of Birmingham and Higher Education Academy. pp.39-56.

Lawson, D., Croft, T. and Halpin, M., 2003. Good Practice in the Provision of Mathematics Support Centres. 2nd ed. Birmingham, UK: LTSN Maths, Stats and OR Network. Available at: http://www.mathcentre.ac.uk/resources/guides/goodpractice2E.pdf [Accessed 15 May 2019].

Lee, S., 2005. A Postgraduate's Experience of Teaching. MSOR Connections, 5(4), pp.38-39.

Mathematical Association of America (MAA), 2003. Guidelines for Programs and Departments in Undergraduate Mathematical Sciences. Washington, D.C.: Mathematical Association of America.

National Forum, 2016. National Professional Development Framework for all staff who teach in Higher Education. Dublin, Ireland: National Forum for the Enhancement of Teaching and Learning in Higher Education. Available at: http://www.teachingandlearning.ie/wpcontent/uploads/2016/09/PD-Framework-FINAL-1.pdf [Accessed 15 May 2019].

National Research Council, 1991. Moving Beyond Myths: Revitalizing Undergraduate Mathematics. Washington, D.C.: National Academy Press. 
Neves, J. and Hillman, N., 2016. The 2016 Student Academic Experience Survey. York, UK: The Higher Education Academy. Available at: http://www.hepi.ac.uk/wpcontent/uploads/2016/06/Student-Academic-Experience-Survey-2016.pdf [Accessed 15 May 2019].

O'Sullivan, C., Mac an Bhaird, C., Fitzmaurice, O. and Ní Fhloinn, E., 2014. An Irish Mathematics Learning Support Network (IMLSN) report on student evaluation of mathematics learning support: insights from a large scale multi-institutional survey. Available at:

http://mural.maynoothuniversity.ie/6890/1/CMAB IMLSNFinalReport.pdf [Accessed 15 May 2019].

Perkin, G. Croft, T. and Lawson, D., 2013. The extent of mathematics support in UK higher education-the 2012 survey. Teaching Mathematics and its Applications, 32(4), pp.165-172. https://doi.org/10.1093/teamat/hrt014

Pfeiffer, K., Cronin, A. and Mac an Bhaird, C., 2016. The key role of tutors in mathematics learning support - a report of the 10th annual IMLSN workshop. MSOR Connections, 15(1), pp.39-46. https://doi.org/10.21100/msor.v15i1.367

Quality Assurance Agency (QAA), 2015. Subject Benchmark Statement: Mathematics, Statistics and Operational Research. Gloucester, UK: UK Quality Assurance Agency for Higher Education.

Rishel, T.W., 1999. A handbook for mathematics teaching assistants. Washington, DC: Mathematical Association of America.

Solomon, Y., Croft, T. and Lawson, D., 2010. Safety in numbers: mathematics support centres and their derivatives as social learning spaces. Studies in Higher Education, 35(4), pp.421-431.

https://doi.org/10.1080/03075070903078712

UK Professional Standards Framework (UKPSF), 2011. The UK Professional Standards Framework for teaching and supporting learning in higher education. Available at:

https://www.heacademy.ac.uk/system/files/downloads/uk professional standards framework.pdf [Accessed 15 May 2019]. 